\title{
HETEROTOPIC PREGNANCY AFTER SPONTANEOUS CONCEPTION- A RARE ENTITY
}

\author{
Devyani Sawai ${ }^{1}$, Susheel Kumar Sharma², Devashish Singh Sawai ${ }^{3}$, Savita Singhal ${ }^{4}$, Krishna Dahiya ${ }^{5}$
}

\author{
1M.S, Department of Obstetrics and Gynaecology, PGIMS, Rohtak. \\ ${ }^{2}$ M.D, Department of Medicine, Oscar Hospital, Rohtak. \\ ${ }^{3}$ Assistant Professor, Department of Orthodontics, Doon Medical College, Dehradun, Uttarakhand. \\ 4 Professor, Department of Obstetrics and Gynaecology, PGIMS, Rohtak. \\ 5 Professor, Department of Obstetrics and Gynaecology, PGIMS, Rohtak.
}

HOW TO CITE THIS ARTICLE: Sawai D, Sharma SK, Sawai DS, et al. Heterotopic pregnancy after spontaneous conception- a rare entity. J. Evolution Med. Dent. Sci. 2017;6(76):5469-5470, DOI: 10.14260/Jemds/2017/1186

\section{PRESENTATION OF CASE}

We report a rare case of Heterotopic pregnancy in a natural conception cycle, where a clinically stable patient with low risk factors which was picked up on USG. This case report emphasises the importance of holistic approach through USG in managing these patients.

Heterotopic pregnancy is diagnosed as the presence of simultaneous gestations at two or more implantation sites. Its occurrence is rare in spontaneous conception with an incidence of 1:30000, whereas in assisted reproductive techniques its incidence is found to be as high as one percent. It was reported in the year 1708 as an autopsy finding.

A 35 years old, G5P2A2 with two live children, presented in gynaec outdoor with 5 weeks +1 day amenorrhoea for routine antenatal checkup. Her transvaginal ultrasound revealed bulky uterus with a gestational sac of size $9.5 \times 9.5 \times$ $8.7 \mathrm{~mm}$ corresponding to $5+1$ weeks. Another yolk sac $(12.7$ x $11.2 \times 8.6 \mathrm{~mm}$ ) was seen in left adnexa corresponding to $5+$ 5 week, which was suggestive of heterotopic pregnancy. The Doppler study also confirmed the heterotopic study.

She had no history of any intrauterine contraceptive device usage or any previous sexually transmitted infections or pelvic inflammatory disease. She denied having taken any infertility treatment. There was no history of any pelvic/tubal pathology or ectopic pregnancy. She was a non-smoker.

She was a known case of hypothyroidism on treatment since past 3 years. Apart from this, her past medical and surgical history was unremarkable. On examination, her pulse rate was $86 \mathrm{bpm}$, BP was 128/82 $\mathrm{mmHg}$, abdomen was soft, non-tender on pervaginal examination, the uterus was bulky, bilateral adnexa were free and non-tender and cervical motion tenderness was present.

\section{PATHOLOGICAL DISCUSSION}

Her serum $\beta$-HCG was $11180 \mathrm{mIU} / \mathrm{mL}$, urine routine was normal, $\mathrm{Hb}$ was $12.4 \mathrm{gm} / \mathrm{dL}$. Clinically vitals being stable, and since patient was already having two children and she did not want further issues, decision for medical management by Inj. methotrexate was taken. Inj. methotrexate $50 \mathrm{mg}$ was given intramuscularly and suction evacuation was done on $2^{\text {nd }}$ day and products sent for histopathological examination.

Financial or Other, Competing Interest: None.

Submission 22-06-2017, Peer Review 24-08-2017,

Acceptance 31-08-2017, Published 21-09-2017.

Corresponding Author:

Dr. Devyani Sawai,

H. No. 476, Ground Floor,

Omaxe - City, Rohtak, Haryana.

E-mail: devyani7187@gmail.com

DOI: $10.14260 /$ jemds $/ 2017 / 1186$
Serial $\beta$-HCG levels were monitored, which showed a significant decline in titre ( $\beta$-HCG after 72 hours fell optimally to $1168 \mathrm{mIU} / \mathrm{dL}$. Histopathological examination confirmed products of conception.

\section{DISCUSSION OF MANAGEMENT}

Heterotopic Pregnancy is diagnosed by the presence of multiple pregnancies with one or more intrauterine pregnancies coexisting with an ectopic pregnancy. ${ }^{1}$ The ectopic pregnancy can be tubal, ovarian, abdominal, cervical or cornual. Out of these, tubal ectopics are the most common.

Majority of reported heterotopic pregnancies are of singleton intrauterine pregnancies. However, triplet and quadruplet heterotopic pregnancies have also been reported. ${ }^{1}$ The increased incidence of heterotopic gestation may be due to increased rate of ovulation induction and in vitro fertilisation. ${ }^{2}$ Previous tubal surgeries may also cause an increased risk. A heterotopic pregnancy, although extremely rare, can still occur from a natural conception. ${ }^{3}$ The present case that we report is of a heterotopic pregnancy developed during a spontaneous conception without any known risk factors like PID, tuberculosis, infertility, etc.

Early diagnoses of Heterotopic pregnancy is difficult due to the absence of clinical symptoms. ${ }^{4}$ Reece et al defined abdominal pain, adnexal mass, peritoneal irritation and enlarged uterus as suspicious signs. In our present case, the patient remained asymptomatic and was diagnosed as having heterotopic pregnancy on ultrasonography. Thus, transvaginal ultrasound and assessment of whole pelvis, even in the presence of intrauterine pregnancy can be an important aid in the diagnosis of HP.

A review article in 2008, which analysed six studies showed that TVS has a sensitivity of $74 \%-84 \%$ in diagnosing ectopic pregnancy. ${ }^{5}$ Another comparative study of 192 cases of Heterotopic pregnancy in 2012 showed that only $1 / 3$ of the cases were diagnosed by USG. ${ }^{6}$

Serial $\beta$-HCG levels are not of much significance in diagnosis of HP as subnormal hormone production by ectopic pregnancy may be masked by the increased placental production from intrauterine pregnancy.7,8 In the present case study, the $\beta$-HCG levels at the time of admission was $11180 \mathrm{mIU} / \mathrm{mL}$ which was significantly higher. The $\beta$-HCG levels fell to $1168 \mathrm{mIU} / \mathrm{mL}$ after 72 hours.

The standard treatment protocol for ectopic pregnancy is surgery by laparoscopy or laparotomy, depending upon the condition of the patient. Main aim of the surgery should be preservation of intrauterine pregnancy. Medical management for an ectopic pregnancy with an intact tube is local injection of KCL. Treatment with intramuscular methotrexate is also a safe option in cases where continuation of intrauterine 
pregnancy is not desired. The prognosis of intrauterine pregnancy is favourable in $60 \%-70 \%$ cases. $^{9}$ Smith and Siddique reported a survival rate of $35 \%-54 \%$. In a study by Tal et al, $66 \%$ proceeded to term pregnancy. In another study by Barren et al, $69 \%$ proceeded to term. ${ }^{10}$ Improvement in intrauterine pregnancy survival rate is probably due to better diagnostic and treatment advancements and better followup of patients.

Thus, we conclude that management of heterotopic pregnancy should be individualised based on the clinical condition of the patient and the will of the patient to continue the intrauterine pregnancy or not. In our present study, our patient already had two live issues and was not willing to continue this pregnancy, so a decision of termination of pregnancy was taken after taking written and informed consent of the patient.

\section{CONCLUSION}

Heterotopic pregnancy can occur even in the absence of any predisposing risk factors, and the detection of an intrauterine pregnancy does not exclude the possibility of the simultaneous existence of an ectopic pregnancy. Therefore, in all patients of reproductive age group, even in the presence of an intrauterine pregnancy, a complete ultrasonographic review of the whole pelvis including adnexa should be done to rule out the presence of heterotopic pregnancy. Management of heterotopic pregnancy should be individualised depending upon the clinical condition of the patient and the will of the patient to continue the intrauterine pregnancy or not. This rare obstetrical phenomenon carries a significant maternal morbidity and mortality due to risk of ruptured ectopic pregnancy. Therefore, early diagnosis and management of heterotopic pregnancy is important.

\section{FINAL DIAGNOSIS}

Heterotopic Pregnancy after Spontaneous Conception.

\section{REFERENCES}

[1] Govindarajan MJ, Rajan R. Heterotopic pregnancy in natural conception. J Hum Reprod Sci 2008;1(1):37-8.

[2] Farquhar CM. Ectopic pregnancy. Lancet 2005;366(9485):583-91.

[3] Jerrard D, Tso E, Salik R, et al. Unsuspected heterotopic pregnancy in a woman without risk factors. Am J Emerg Med 1992;10(1):58-60.

[4] Cohen J, Mayaux MJ, Guihard-Moscato MI, et al. In vitro fertilization and embryo transfer, a collaborative study of 1163 pregnancies on the incidence and risk factors of ectopics pregnancies. Hum Reprod 1986;1(4):2558.

[5] Lyons EA, Levi CS, Sidney M. In: Dashefsky in diagnostic ultrasound. $2^{\text {nd }}$ edn. Rumak CM, Wilson SR, Charboneau WK, eds. Volume 2. Mosby; 1998:pp 999.

[6] Stein JC, Wang R, Adler N, et al. Emergency physician ultrasonography for evaluating patients at risk for ectopic pregnancy: a meta analysis. Ann Emerg Med 2010;56(6):674-83.

[7] Practice Committee of American Society for Reproductive Medicine. Medical treatment of ectopic pregnancy. Fertil steril 2008;90(5 Suppl):S206-12.

[8] DeVOE RW, Pratt JH. Simultaneous intrauterine and extrauterine pregnancy. Am J Obstet Gynecol 1948;56(6):1119-26.

[9] Hoover KW, Tao G, Kent CK. Trends in the diagnosis and treatment of ectopic pregnancy in te united states. Obstet Gynaecol 2010;115(3):495-502.

[10] Bright DA, Gaupp FB. Heterotopic pregnancy: a reevaluation. J Am Board Fam Pract 1990;3(2):125-8. 